\title{
Beta-Aminobutyric Acid Measurement
}

National Cancer Institute

\section{Source}

National Cancer Institute. Beta-Aminobutyric Acid Measurement. NCI Thesaurus. Code C154765.

The determination of the amount of beta-aminobutyric acid present in a sample. 